\title{
A nonsmooth Stackelberg equilibrium problem via mixed variational inequalities
}

\section{JUE LU, LI-WEN ZHOU, YI-BIN XIAO and NAN-JING HUANG}

\section{ABSTRACT.}

In this paper, we introduce and study a class of nonsmooth Stackelberg equilibrium problems with differential revenue functions and nonsmooth cost functions. First, we describe the best response set of the follower and the best strategy set of the leader for the considered nonsmooth Stackelberg equilibrium problem via mixed variational inequalities. Then, by using the resolvent operator method and the Banach fixed point theorem, we show the existence and uniqueness of its solution.

Acknowledgements. This work was supported by the National Natural Science Foundation of China (11471230, 11671282, 11771067) and the Applied Basic Project of Sichuan Province (2019YJ0204).

The authors are grateful to the editors and the referees for their valuable comments and suggestions.

\section{REFERENCES}

[1] Agiza, H. N. and Elsadany, A. A., Chaotic dynamics in nonlinear duopoly game with heterogeneous players, Appl. Math. Comput., 149 (2004), 843-860

[2] Bakir, N. O., A Stackelberg game model for resource allocation in cargo container security, Ann. Oper. Res., 187 (2011), 5-22

[3] Bauschke, H. H. and Combettes, P. L., Convex Analysis and Monotone Operator Theory in Hilbert Spaces, Springer-Verlag, Berlin, (2011)

[4] Dempe, S. and Franke, S., Solution algorithm for an optimistic linear Stackelberg problem, Comput. Oper. Res., 41 (2014), 277-281

[5] Dubiel-Teleszynski, T., Nonlinear dynamics in a heterogeneous duopoly game with adjusting players and diseconomies of scale, Commun. Nonlinear Sci. Numer. Simul., 16 (2011), 296-308

[6] Fang, H., Xu L. and Choo, K. R., Stackelberg game based relayse lection for physical layer security and energy efficiency enhancement in cognitive radio networks, Appl. Math. Comput., 296 (2017), 153-167

[7] Ferreira, F. A., Ferreira, F., Ferreira M. and Pinto, A. A., Flexibility in a Stackelberg leadership with differentiated goods, Optimization, 64 (2015), 877-893

[8] Han, Y. and Huang, N. J., Lower semicontinuity of solution mappings for parametric fixed point problems with applications, Oper. Res. Lett., 45 (2017), 533-537

[9] Hendrix, E. M. T., On competition in a Stackelberg location-design model with deterministic supplier choice, Ann. Oper. Res., 246 (2016), 19-30

[10] Julien, L. A., A note on Stackelberg competition, J. Econ., 103 (2011), 171-187

[11] Konnov, I. V. and Volotskaya, E. O., Mixed variational inequalities and economic equilibrium problems, J. Appl. Math., 6 (2002), 289-314

[12] Liou, Y. C., Schaible, S. and Yao, J. C., Supply chain inventory management via a Stackelberg equilibrium, J. Ind. Manag. Optim., 2 (2006), 81-94

Received: 09.04.2019; In revised form: 19.08.2019; Accepted: 26.08.2019

2010 Mathematics Subject Classification. 90C30, 91B52, $49 J 40$.

Key words and phrases. nonsmooth Stackelberg equilibrium problem, mixed variational inequality, fixed point.

Corresponding author: Nan-jing Huang; nanjinghuang@hotmail.com 
[13] Lu, J., Xiao, Y. B. and Huang, N. J., A Stackelberg quasi-equilibrium problem via quasi-variational inequalities, Carpathian J. Math., 34 (2018), 355-362

[14] Murphy, F. H., Sherali, H. D. and Soyster, A. L., A mathematical programming approach for determining oligopolistic market equilibrium, Math. Program., 24 (1982), 92-106

[15] Nagy, S., Stackelberg equilibria via variational inequalities and projections, J. Global Optim., 57 (2013), 821-828

[16] Novak, A. J., Feichtinger, G. and Leitmann, G., A differential game related to terrorism: Nash and Stackelberg strategies, J. Optim. Theory Appl., 144 (2010), 533-555

[17] Sinha, A., Malo, P., Frantsev, A. and Deb, K., Finding optimal strategies in a multi-period multi-leader-follower stackelberg game using an evolutionary algorithm, Comput. Oper. Res., 41 (2014), 374-385

[18] Stackelberg, H., Market Structure and Equilibrium, Springer-Verlag, Berlin, (2011)

[19] Stanford, W., Pure strategy Nash equilibria and the probabilistic prospects of Stackelberg players, Oper. Res. Lett., 38 (2010), 94-96

[20] Viswanathan, S. and Wang, Q. N., Discount pricing decisions in distribution channels with price-sensitive demand, Europ. J. Oper. Res., 149 (2003), 571-587

[21] Xiao, Y. B., Fu, X. and Zhang, A., Demand uncertainty and airport capacity choice, Transp. Res. Part B, 57 (2013), 91-104

[22] Yang, H. X., Luo, J. W. and Zhang, Q. H., Supplier encroachment under nonlinear pricing with imperfect substitutes: Bargaining power versus revenue-sharing, Europ. J. Oper. Res., 267 (2018), 1089-1101

\author{
SHAOXING UNIVERSITY \\ SCHOOL OF MATHEMATICS \\ PHYSICS AND INFORMATION SCIENCE \\ HuAncheng West RD. No.508, 312000, ShaOxing, P. R. ChinA \\ E-mail address: admiral_lu@hotmail.com \\ SOUthWest Petroleum University \\ School of Sciences, Xindu RoAd 8, 610500, Chengdu, P. R. China \\ E-mail address: zhouliwen@live.cn
}

University of ElECTRONIC SCIENCE AND TECHNOLOGY OF CHINA

SCHOOL OF MATHEMATICAL SCIENCES

West Hi-Tech.Zone Xiyuan Ave No.2006, 611731, Chengdu, P. R. China

E-mail address: xiaoyb9999@hotmail.com

DEPARTMENT OF MATHEMATICS

SICHUAN UNIVERSITY

WANGJIANG ROAD 29, 610064, CHENGDU, P. R. CHINA

E-mail address: nanjinghuang@hotmail.com 